Vol 3, No. 1, Agustus 2020: 213 -221, DOI: https://doi.org/10.34007/iehss.v3i1.271

\title{
Representasi dan Komodifikasi Kepiluan dalam Film Dancing In The Rain
}

\section{Heartbreaking Representation and Commodification in the film Dancing In The Rain}

\author{
Ilma Saakinah Tamsil \\ Program Studi Ilmu Komunikasi, Fakultas Ilmu Sosial dan Ilmu Politik, \\ Universitas Medan Area, Indonesia.
}

Diterima: 29 Juli 2020; Disetujui: 02 Agustus 2020; Dipublish: 04 Agustus 2020 *Email: ilmapavi@gmail.com

\begin{abstract}
Abstrak
Film yang mengangkat cerita dan tema tentang penderitaan orang lain sebagai sisi humanis selalunya bertujuan untuk menggugah emosi dan perasaan penontonnya. Film seperti ini banyak mendapat respons positif dari berbagai pihak terutama film yang menekankan kepada kepiluan. Tujuan dari penulisan ini adalah untuk menganalisis struktur naratif film Dancing In The Rain sebagai representasi dan komodifikasi kepiluan bagi penonton. Penulis menggunakan jenis penelitian deskriptif kualitatif mana Representasi dan Komodifikasi Kepiluan dalam Film Dancing In The Rain dianalisis melalui analisis struktur naratif menurut Tzvetan Todorov, pemaparan nilai moral di dalam film, dan kaitan dengan industri budaya sebagai media pembentukan citra. Bagaimana kesedihan dan kepiluan penderita autis dikomodifikasikan sebagai produk yang menghibur dan memotivasi yang menontonnya. Kesimpulannya, realitas di dalam film dapat menjadi sebuah pembelajaran melalui representasi dan komodikasi kepiluan memberikan gambaran mengenai kondisi, pengalaman serta masalah yang dihadapi tokoh utama (penderita autis) berjuang menghadapi kehidupan.
\end{abstract}

Kata Kunci: Analisis Struktur Naratif, Nilai Moral, Representasi, Komodifikasi, Industri Budaya

\begin{abstract}
The film tells stories and theme about the suffering of others as a humanist always aim to arouse the emotions and feelings of the audiences. This Film get a lot of positive responses from various parties, especially films that emphasize the sorrow. The purpose of this paper is to analyze the narrative structure of the film Dancing In The Rain as a representation and commodification of depression for the audience. The author uses a qualitative descriptive study in which the representation and commodification of heartache in Dancing In The Rain movie is analyzed through the analysis of narrative structure according to Tzvetan Todorov, the presentation of moral values in the film, and the relation with the culture industry as a medium for image formation. How the sadness and heartache of autistic sufferers is commodified as a product that entertains and motivates the audiences. The conclusion, the reality in the film will be a learning through representation and the commodification of heartache give a description of the conditions, experiences and problems faced by the main character (autistic sufferers) struggling to faced life.
\end{abstract}

Keywords: Narrative Structure Analysis, Moral Value, Representation, Commodification, Cultural Industry

How to Cite: Tamsil, I.S (2020). Representasi dan Komodifikasi Kepiluan dalam Film Dancing In The Rain. Journal of Education, Humaniora and Social Sciences (JEHSS). 3 (1): 127-131.

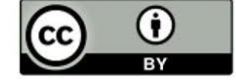




\section{PENDAHULUAN}

Film merupakan media komunikasi yang berbentuk gambar yang bergerak serta membentuk suatu cerita berupa tayangan audio visual untuk menyampaikan pesan kepada audiens. Media massa merupakan fokus atau kajian utama dalam komunikasi. Media massa merupakan channel yang digunakan dalam sebuah proses komunikasi massa yaitu digunakan untuk diarahkan kepada orang banyak dalam menyampaikan dan menyebarkan informasi berupa pesan berita, peristiwa atau produk budaya yang mempengaruhi dan merefleksikan suatu keadaan masyarakat.

Film secara sederhana merupakan susunan gambar yang ada di dalam seluloid, kemudian diputar dengan menggunakan teknologi proyektor yang dapat menawarkan nafas demokrasi dan kritikan sosial sehingga dapat ditafsirkan dalam berbagai makna. Film juga dapat menawarkan berbagai pesan sehingga dapat dimanfaatkan dalam berbagai kegunaan. Oleh kerana itu, film menjadi begitu menarik untuk dikaji dari berbagai aspek (Prakosa, 2001).

Perjalanan dan perkembangan film Indonesia dari tahun ke tahun banyak meninggalkan sejarah yang sangat menarik. Mulai dari vakum selama puluhan tahun dan bangkit kembali pada akhir 1990an, film-film Indonesia banyak yang diikutkan dalam festival-festival film internasional. Salah satu kebangkitan baru dalam dunia perfilman Indonesia ditandai dengan terdapat beberapa pembuat film di Indonesia yang mengungkap isu-isu tentang hak asasi manusia, perubahan sosial serta globalisasi (Dalimunthe, 2020; Ayun, 2015; Briandana, 2015). Perkembangan terkini dan bangkitnya gerakan-gerakan baru di dalam perfilman Indonesia tidak dapat dipisahkan dari kejadian-kejadian penting yang terjadi di dalam lingkup nasional seperti perubahan konflik dalam bidang politik, sosial, ekonomi dan budaya. Isu-isu tentang produksi, penyaluran, penayangan, isi dan judul cerita, mencerminkan keadaan sejarah dan budaya masa kini yang berkaitan dengan keadaan sekitar sebagai upaya penciptaan karya seni berupa film.

Perkembangan film di Indonesia tidak dapat lepas dari peran masyarakat dan bagaimana kritikan sosial yang terkandung di dalamnya. Film tidak hanya mempunyai fungsi di dalam masyarakat, tetapi juga memungkinkan untuk mencerminkan dan menyatakan aspek-aspek yang kadang-kadang kurang terlihat jelas di masyarakat. Seperti seni pertunjukan lainnya, film mempunyai fungsi sosial dan estetika. Melalui kedua-dua fungsi ini pernyataan ini kemudian dijelaskan (Pranajaya, 1999).

Fungsi sosial film ditandai dengan kaitan film di dalam kehidupan sosial, ekonomi, politik, etika, kepercayaan dan lain sebagainya. Fungsi estetika pula ditandai dengan kewujudan film sebagai karya seni yang dapat memberikan kesenangan dan keindahan bagi penontonnya (Akim, et. Al., 2019). Kedua-dua fungsi ini secara umumnya terjalin dengan baik dan berterusan serta dapat pula dihubungkan dengan ciri-ciri simbolisme atau perlambangan di dalam masyarakat. Melalui perlambangan, akan wujud sifat-sifat yang mempunyai tempat sendiri untuk dapat dibedakan antara yang baik dengan yang buruk. Menurut Adi Pranajaya, "film tidak dapat mempengaruhi masyarakat untuk mengubah sikap, tetapi film cukup berpengaruh kepada apa yang difikirkan masyarakat terutama tentang sesuatu yang dianggap penting. Pengaruh ini kemudian dipilih bahkan ditolak sesuai dengan faktor-faktor personaliti yang ada di dalam masyarakat (Pranajaya, 1999).

Film yang sukses biasanya adalah film yang mendapat sambutan positif dari penontonnya. Bisa karena jalan ceritanya, siapa pemainnya, sutradaranya serta efek kognitif dan afektif yang diberikan setelah menonton. Film dinilai bagus jika mampu mencerminkan mentalitas sebuah bangsa. "The films of a nation reflect its mentality in a more direct way than other artistic films because films are never the product of an individual and the films address themselves and appeal to the anonymous multitude" (Kracauer, 1947) dan "the most powerfull function of film is the communicative" (Lotman, 1976).

Sejak vakum beberapa tahun dan bangkit kembali, film-film Indonesia sudah mulai melengkapi kriteria ini. Banyak juga film-film Indonesia yang mengikuti ajang festival namun pemutarannya di bioskop hanya bertahan beberapa hari dikarenakan jumlah penontonnya sedikit. Penonton lebih menyukai tema-tema yang mudah dicerna yaitu kembali ke unsur-unsur mendasar 
dalam kehidupan manusia seperti komedi, seks, horor, dan kekerasan (Sasono, et.al., 2011). Dengan kata lain, film-film komersial Indonesia lebih menggunakan prinsip audience approach dengan memasukkan unsur-unsur back to basic yang memang seringkali membahas persoalan diri sendiri sebatas kulitnya saja atau bahkan bertolak belakang dengan keadaan Indonesia sendiri.

Film akan dibahas di dalam penelitian ini adalah Dancing In The Rain. Film ini bercerita tentang Banyu (Dimas Anggara) adalah sosok yang gigih dalam hidupnya. Ia dilahirkan berbeda sejak kecil karena merupakan anak berkebutuhan khusus (autis). Namun, tetap saja ada orangorang yang sayang kepadanya salah satunya adalah Eyang Uti (Christine Hakim). Sejak kecil, Banyu ditelantarkan oleh orang tuanya. Namun, dengan semangat dan percaya diri, Eyang Uti menyimpan sebuah asa kepada Banyu hingga Banyu dewasa nantinya. Eyang Uti sangat setia dan memberikan sebuah optimisme hidup pada Banyu sedari kecil. Pelan-pelan Eyang Uti menyadari ada yang berbeda dengan sosok Banyu. Banyu yang tengah tumbuh menjadi remaja mengalami kesulitan berinteraksi dengan lingkungannya. Satu hal yang tidak biasa, namun membuat Banyu terasa istimewa. Dibalik perbedaan yang dimiliki Banyu, ia ternyata adalah sosok yang jujur dan penuh kasih sayang, persis seperti apa yang selalu diajarkan oleh Eyang Uti. Tidak hanya Eyang Uti yang menyayangi Banyu, Radin dan Kinara merasakan ada hal yang istimewa pada sosok Banyu. Ketiganya kemudian bersahabat hingga dewasa. Film ini menjadi menarik untuk dijadikan objek analisis karena karakter autis yang dimainkan oleh Dimas menjadi salah satu stimulus kepiluan orang yang menontonnya. Dari film ini, Dimas berhasil meraih pemeran utama pria terpuji film bioskop pada Bandung Film Festival For Commendable Film Main Actor pada 2019 (Festival Film Bandung (FFB) 2019 ke 32 digelar di kota Baru Parahyangan, Kabupaten Bandung Barat, Jumat, 22 November 2019).

\section{METODE PENELITIAN}

Jenis penelitian ini adalah deskriptif kualitatif karena metode ini merupakan sebuah metode penelitian yang naturalistik karena penilaiannya dilakukan pada kondisi alamiah (Sugiyono, 2007). Dengan kata lain ini merupakan jenis penelitian dengan proses memperoleh data bersifat apa adanya dan lebih menekankan makna pada hasilnya.

Sumber data yang digunakan penelitian ini terbagi dua yaitu data primer dan data sekunder. Unit analisis sebagai data primer adalah Film Dancing In The Rain (2018) sedangkan data sekunder diperoleh dari buku, jurnal, bacaan, internet serta informasi-informasi yang mendukung penelitian ini. Penelitian ini menggunakan dua teknik yaitu studi bahan visual dan studi pustaka.

Penelitian ini akan dianalisis dan dituangkan dalam bentuk deskriptif menggunakan analisis struktur naratif menurut Tzvetan Todorov, pemaparan nilai moral di dalam film, serta kaitan dengan industri budaya sebagai media pembentukan citra.

\section{HASIL DAN PEMBAHASAN}

\section{Analisis Struktur Naratif Film Dancing In The Rain menurut Tzvetan Todorov}

Narasi merupakan cerita yang diurutkan atau serangkaian kejadian peristiwa yang di dalamnya terdapat satu atau beberapa tokoh yang mengalami kejadian atau serangkaian konflik. Kejadian itu merupakan unsur dari sebuah pokok narasi dan ketiganya secara kesatuan dapat dikatakan sebagai plot atau alur. Dengan demikian, narasi adalah cerita berdasarkan alur (Sobur, 2014). Narasi berasal dari kata latin narre, yang artinya "membuat tahu" dengan begitu, narasi berhubungan dengan usaha untuk memberitahu sesuatu atau peristiwa (Sobur, 2014). Sesuatu atau peristiwa yang dimaksud disini adalah peristiwa yang mempunyai rangkaian atau urutan peristiwa.

Terdapat unsur penting pada sebuah narasi yaitu unsur perbuatan atau tindakan, plot, karakter dan latar. Plot adalah dasar dari semua unsur yang terdapat dalam narasi karena menggambarkan dari jalannya sebuah cerita. Karakter merupakan pemeran atau tokoh yang terdapat dalam sebuah cerita, dapat berupa "the hero, the coward, the lover, the friend and so on" sedangkan latar berupa lokasi dimana, kapan waktunya dan alur cerita yang diambil. Narasi 
adalah jenis pengembangan suatu paragraf bentuk tulisan, dimana didalamnya menjelaskan tentang rangkaian kejadian dari waktu ke waktu mulai urutan awal, tengah dan akhir. Naratif pula merupakan teks yang terstrukturkan oleh rangkaian waktu dari berbagai peristiwa yang ditampilkan (Thawites, Davis and Mules, 2002). Analisis struktur naratif bertujuan untuk mendapatkan susunan teks. Untuk itu, pertama-tama harus ditentukan oleh satuan-satuan cerita dan fungsinya (Zaimar, Okke K.S, 1990).

Naratif dalam Film Dancing in the Rain dimulai dari kisah satu ke kisah lainnya yang saling berhubungan sehingga membentuk rangkaian visual yang bermakna. Naratif merupakan perpaduan unsur pokok dalam cerita meliputi plot, setting serta karakter. Dancing in the Rain adalah film drama keluarga Indonesia yang dirilis pada 18 Oktober 2018, disutradarai oleh Rudy Aryanto yang dibintangi oleh Deva Mahendra, Dimas Anggra, Bunga Zainal, Christine Hakim. Film ini menceritakan tentang kisah anak berkebutuhan khusus (autis) yang menambah daftar film Indonesia bertemakan autisme sebelumnya yaitu My Idiot Brother (2014) (My Idiot Brother adalah film drama Indonesia yang dirilis pada 2014 yang di sutradarai oleh Alyandra dan produser Hamdhani dan Ferry. Diproduksi oleh Film One Production. Film ini diangkat dari novel berjudul sama My Idiot Brother karangan Agnes Davonar) dan Malaikat Kecil (2015) (Malaikat Kecil adalah film drama Indonesia yang dirilis pada 8 Oktober 2015. Di sutradari oleh Richyana dan Produser Arri Wahyudi Edimar serta Inggris Rhemanty. Diproduksi oleh Atlantis Pictures. ).

Film ini mengisahkan Banyu (Dimas Anggara) yang ditelantarkan orang tuanya karena menderita autis. Banyu akhirnya dirawat dan dibesarkan oleh Eyang Uti (Christrine Hakim) dengan penuh kasih sayang. Dengan adaya film ini, diharapkan mampu mengedukasikan masyarakat tentang kehidupan anak autis dan setidaknya mampu mengubah pandangan masyarakat terhadap anak autis. Masih banyak yang belum tahu autis itu apa, selama ini kerap dianggap idiot padahal banyak diantara mereka yang memiliki kecerdasan di atas rata-rata (Ketua Forkasi (Forum Komunikasi Orang Tua Indonesia) Sumatera Barat, Krisno Marsel). Dancing in the Rain menceritakan kisah Banyu mengalami kesulitan berinteraksi dengan lingkungannya, namun walau begitu Banyu memiliki dua sahabat yakni Radin dan Kinara yang sangat peduli dan sayang kepadanya. Sebagai penyandang autis, Banyu digambarkan kerap dibedakan karena memiliki perilaku yang berbeda. Namun Banyu memiliki kecerdasan di atas rata-rata dan memiliki kemampuan akademik yang luar biasa yang dibuktikannya dengan menjadi juara di kompetisi sains. Dancing in the Rain juga mampu membuat penonton merasakan bagaimana beratnya dan belum siapnya sebagian masyarakat menerima penyandang autis.

Kasih sayang yang tulus di antara Eyang Uti dan Banyu melahirkan ikatan emosi yang kuat serta ketabahan Eyang Uti merawat Banyu. Karakter Eyang Uti dapat kita jumpai pada karakter Corrine Morgan di dalam film Miracle Run (Film ini produseri oleh John J Anderson dan Randi Richmond, disutradarai oleh Gregg Champion pada 2004) yang ditinggalkan oleh suaminya karena memiliki anak kembar penyandang autis. Corrine yang tegar pun berusaha merawat kedua anaknya sendiri. Ia selalu berusaha agar anaknya mendapatkan perlakuan yang sama seperti anak biasa. Namun banyak sekolah yang menolak mentah-mentah karena autis yang diderita kedua anaknya. Meski berat, perjuangan Corrine untuk mendidik anaknya berbuah manis karena keduanya bisa meraih kesuksesan dan mematahkan stigma mengenai penyandang autis. Radin sebagai sahabat Banyu ternyata mengalami penyakit yang sama di derita oleh ayahnya. Ikatan emosi yang kuat juga dapat dijumpai ketika pertandingan basket, Radin terjatuh kemudian mengalami koma dan harus mendapatkan donor jantung. Banyu rela menolong Radin. Walaupun keadaannya seperti itu, Banyu membalas kasih sayang Eyang Uti dan sahabatnya dengan caranya sendiri.

Struktur narasi menurut Tzvetan Todorov dimulai dari adanya keseimbangan yang kemudian terganggu oleh adanya masalah-masalah yang timbul dalam cerita. Alur ditandai oleh puncak atau klimaks dari perbuatan dramatis dalam rentang laju narasi. Narasi di akhiri oleh upaya untuk menghentikan gangguan sehingga keseimbangan (ekuilibirum) tercipta kembali (Eriyanto, 2013). Dengan kata lain, Tzvetan Todorov, mengatakan bahwa semua cerita di mulai dengan keseimbangan dimana beberapa potensi pertentangan berusaha diseimbangkan pada 
suatu waktu. Walau sangat sederhana yaitu setiap cerita akan memiliki awal, pertengahan dan sebuah akhir.

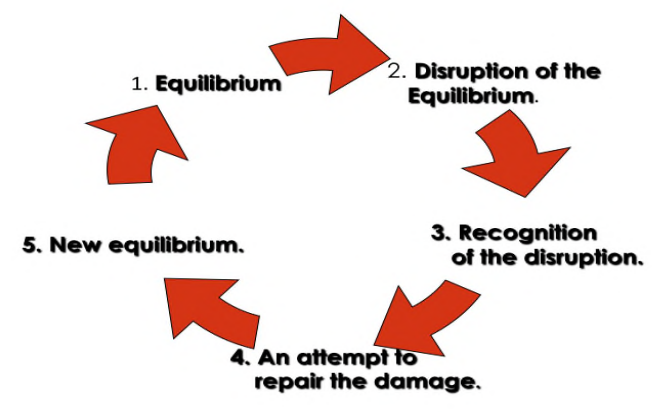

Struktur narasi film Dancing In The Rain meliputi fase ekuilibrium-kekacauan-ekuilibrium yang dibagi ke dalam 5 pembabakan yaitu :

1. Kondisi awal narasi pada umumnya diawali dengan situasi normal, keterlibatan dan keseimbangan. Di bagian ini terdapat pengenalan tokoh, latar, suasana dan lainnya. Di dalam film pada bagian awal scene, terlihat Banyu berada di tengah jalan, di bawah hujan deras dan lalu lalang kendaraan, Banyu membawa sebuah amplop berisikan peta Rumah Sakit serta foto Banyu Radin dan Kirana. Scene ini adalah scene flash forward yang membawa inti cerita film ini. Kemudian menuju adegan ketika Banyu pertama kali sekolah diantar Eyang Uti. Di dalam kelas, Banyu tidak seperti anak biasanya. Banyu sibuk dengan dunianya sendiri, bertingkah aneh, dan suka mengulang. Banyu akhirnya pindah sekolah. Scene ketika Banyu berjalan kaki sewaktu pulang sekolah, Banyu mendapat perlakuan tidak menyenangkan oleh anak-anak seumurnya, namun di situ dia bertemu Radin dan Kinara yang membantunya. Disitulah menjadi agedan pertama kalinya persahabatan Banyu dengan Radin dan Kinara bermula. Setiap pulang sekolah, mereka selalu bermain di bawah hujan sampai akhirnya mereka duduk di bangku kuliah. Radin memiliki hobi olahraga basket dan mendapat kesempatan bertanding. Dengan memberikan 2 tiket, Radin mengajak Banyu dan Kinara untuk melihat pertandingannya. Banyu sangat menonjol pada mata pelajaran sains dan selalu dapat nilai tertinggi. Kinara sendiri ternyata memiliki penyakit meningitis namun Kinara menyembunyikan penyakit ini dari kedua sahabatnya, berusaha untuk tetap tampil prima di hadapan sahabatnya.

2. Gangguan (distruption) terhadap keseimbangan bagian atau struktur kedua dari narasi adalah tentang adanya tokoh yang merusak keharmonisan, keseimbangan, keteraturan. Kehidupan yang normal dan teratur setelah adanya tokoh atau keadaan tindakan tertentu berubah menjadi tidak teratur. Disini terjadi awal pertikaian, yaitu bagian dimana terjadi konflik awal yang dialami oleh tokoh dalam cerita. Bagian kedua dari narasi adalah gangguan dan mulainya terjadi pertikaian. Pada struktur naratif kedua ini tergambar saat Ibu Radin tidak suka Radin bergaul dengan Banyu karena Radin selalu menjadi pelindung Banyu. Ibu Radin datang ke rumah Eyang Uti dan bertindak kasar kepada Banyu. Ibu Radin berhasil memfitnah Banyu di depan Radin karena tidak sengaja Ibu Radin terdorong hingga terjatuh. Hal ini membuat Radin menjauhi Banyu. Ibu Radin juga menelepon Kinara mengatakan agar Kinara jangan pernah menghubungi Radin lagi dan berhenti menjadikan Radin sebagai pelindung untuk mendapat belas kasihan karena kekurangan yang dimiliki Kirana.

3. Kesadaran akan terjadinya gangguan. Pada tahap ketiga, gangguan (distruption) makin besar dan dampaknya makin dirasakan. Pada tahap ini gangguan pada umumnya mencapai titik puncak (klimaks) yaitu puncak pertikaian yang dialami oleh tokoh dan merupakan inti

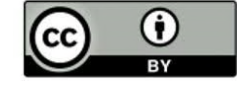


dari cerita yang disampaikan. Radin, Banyu dan Kinara sama-sama menjalani keadaan masingmasing. Radin jatuh ketika bermain tanding basket dan tidak sadarkan diri sehingga harus dilarikan ke rumah sakit. Radin mengalami gagal jantung dan harus mendapat donor jantung. Banyu sangat sedih dan menangis kepada Eyang Uti bahwa Banyu ingin sekali menolong Radin dengan mendonorkan jantungnya. Radin digambarkan sedang terbaring dengan alat medis lengkap di tubuhnya. Kirana pula digambarkan mendapat kabar yang kurang baik dari penyakitnya sehingga membuatnya harus lumpuh. Di bagian ini diiringi musik yang mendukung suasana dramatis.

4. Upaya memperbaiki. Pada tahap ini, narasi biasanya berisi tentang hadirnya sosok pahlawan (hero) yang berupaya untuk memperbaiki gangguan. Ditahap ini, sudah ada upaya untuk menciptakan keteraturan kembali, meskipun upaya yang digambarkan mengalami kegagalan. Di dalam film diperlihatkan ketika Ibu Radin berlutut memohon maaf kepada Eyang Uti atas kekhilafan yang ia lakukan. Di sisi lain terlihat Banyu berbaring di samping Radin mendonorkan jantungnya sebagai sosok pahlawan yang menyelamatkan nyawa sahabatnya.

5. Pemulihan menuju keseimbangan, menciptakan keteraturan kembali. Tahap ini adalah babak terahir dari suatu narasi, kekacauan yang muncul pada babak dua, berhasil diselesaikan sehingga keteraturan bisa dipulihkan kembali. Disini dapat dikatakan anti klimaks yaitu bagian yang menjelaskan mengenai penyelesaian masalah dalam suatu cerita dan merupakan tanda bahwa cerita tersebut berakhir. Di tahap ini, sudah ada upaya untuk menciptakan keteraturan kembali meskipun upaya itu digambarkan mengalami keadaan yang tidak bisa kembali seperti semula. Ditahap ini, digambarkan Radin sudah pulih dan keluar dari rumah sakit memegang amplop dan ketapel. Di dalam perjalanan pulang dari rumah sakit, Radin meminta pak supir untuk singgah terlebih dahulu ke rumah Eyang Uti untuk bertemu dengan Banyu. Namun Eyang Uti sudah pindah dan rumahnya kosong. Di bagian ini ada flash back ketika Banyu lari dari rumah dan pamit kepada Eyang Uti yang sedang tidur dengan meninggalkan sepucuk surat. Namun Banyu mengalami kecelakaan dan kritis. Di scene ini divisualisasikan keadaan yang semakin dramatis. Eyang Uti menagis membaca surat Banyu dan teringat masa kecilnya. Di saat itu pula, Ibu Radin meminta maaf dan bermohon kepada Eyang untuk mendonorkan jantung Banyu kepada Radin. Scene semakin pilu ketika memperlihatkan kondisi Radin semakin membaik setelah mendapat donor namun disisi lain kondisi Banyu yang telah meninggal dunia dipeluk Eyang Uti sambil bernyanyi lagu Jawa, benar-benar sangat menyentuh emosi penonton karena ternyata Banyu sangat tulus menyanyangi Radin. Ditambah lagi scene ketika Radin menyadari detak jantungnya adalah sahabatnya, scene ketika ibu Radin meminta maaf, Eyang Uti pergi membawa pulang piala olimpiade dan lukisanlukisan Banyu (lukisan yang menyatakan bahwa Banyu menyanyangi kedua sahabatnya). Air mata ditiriskan dari sebuah lukisan-lukisan mereka bertiga, scene ketika Radin berkunjung ke makam Banyu bersama Kirana yang duduk di kursi roda, diiringi OST lagu dari Melly Goeslaw tentang sahabat sejati menjadi penutup yang sangat menyentuh hati. Di bagian ini menjadi babak akhir dari suatu narasi. Kekacauan pada babak kedua berhasil diselesaikan sehingga keteraturan bisa dipulihkan kembali. Banyu ingin menodorkan jantungnya untuk membantu Radin, namun disisi lain ia juga akan berpisah dengan Eyang Uti yang sangat sayang kepadanya. Sebelum pamit kepada Eyang Uti, Banyu menulis sepucuk surat di kamarnya. Di dalam surat itu Banyu menceritakan semuanya. Eyang Uti mengikhlaskan Banyu pergi dan sangat bangga bahwa cucunya sangat mengasihi semua orang.

Film ini sangat berkesan karena didukung oleh pemain-pemain yang sangat mendalami perannya. Dimas Anggara sebagai pemeran utama fokus mendalami peran sebagai penderita autis selama 3 bulan (https://www.tribunnews.com/seleb/2018/10/12/dimas-anggara-harus-tigabulan-dalami-karakter-penyandang-autisme). Sebelum Dimas Anggara, Lukman Sardi dalam film Rectoverso (2013) (Rectoverso adalah sebuah film omnibus atau antologi Indonesia bernuansa cinta yang dirilis pada 14 Februari 2013. Film ini di sutradarai oleh Rachel Maryma, Marcella Zalianty dan Olga Lydia dengan produser Marcella Zalianty dan Eko Kristianto. Film ini diproduksi oleh Keana Production \& Communication merupakan adaptasi dari album musik karya Dewi "Dee" Lestari berjudul Rectoverso yang dirilis pada tahun 2008) dan Dwi Saseno dalam film Malaikat wiw http://mahesainstitute.web.id/ojs2/index.php/jehss

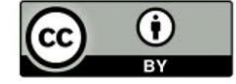

This work is licensed under a Creative Commons Attribution 4.0 
Kecil (2015) juga pernah memerankan penderita autis. Sampai tahun 2018, film Indonesia bertemakan tentang anak berkebutuhan khusus (autis) baru sampai pada film Dancing In The Rain. Christine Hakim yang memainkan peran Eyang Uti sebagai aktris senior tidak diragukan lagi kualitas aktingnya. Pemeran utama pendukung lainnya Bunga Zainal dan Deva Mahendra yang sering mendapatkan peran protagonis di dalam setiap film yang mereka mainkan juga tampil sangat maksimal.

\section{Nilai Moral di dalam Film}

Menurut Suseno (Suseno, 1987) kata moral selalu mengacu kepada baik-buruknya manusia sebagai manusia. Nilai moral adalah nilai-nilai yang berhubungan dengan perbuatan baik dan buruk yang menjadi pedoman kehidupan manusia secara umum dan dapat mendorong manusia untuk bertindak atau melakukan sesuatu, ataupun sebuah sumber motivasi. Nilai moral cenderung mengatur dan membatasi tindakan kita di dalam kehidupan sehari-hari. Dengan arti ini, moral karap kali dikaitkan dengan kodrat dan hakekat manusia yang ingin hidup dalam kenyamanan, dan ketentraman merujuk pada tindakan manusia atau individu yang mengandung nilai positif. Di lihat dari jenisnya, nilai moral terbagi 2 yaitu nilai moral baik dan nilai moral buruk. Di dalam film Dancing in The Rain, nilai moral divisualkan melalui karakter yang dimainkan oleh para pemerannya.

\begin{tabular}{llll}
\hline No & Karakter & Nilai Moral Baik & Nilai Moral Buruk \\
\hline 1. & Banyu & Penyanyang, Baik Hati, Suka Menolong, Jujur & - \\
\hline 2. & Eyang Uti & Baik hati, Penyanyang, Tegar, Sabar & - \\
\hline 3. & Radin & $\begin{array}{l}\text { Melindungi Teman-Temannya, Suka Menolong, } \\
\text { Mandiri, Sopan Santun Ketika Berbicara Dengan Orang } \\
\end{array}$ & Yang Lebih Tua \\
\hline 4. & Kirana & Baik Hati, Sopan Santun Ketika Berbicara Dengan & - \\
& & Orang Yang Lebih Tua & Egois, Sombong, Posesif \\
\hline 5
\end{tabular}

\section{Representasi dan Komodifikasi Kepiluan Film Dancing In The Rain}

Representasi dan Komodifikasi Kepiluan Film Dancing In The Rain dilihat dari peristiwa yang ditandakan sebagai realitas kemudian bagaimana peristiwa tersebut dikonstruksi sebagai realitas oleh media dan melihat bagaimana realitas itu digambarkan. Di dalam film, dapat dilihat dari kamera, pencahayaan, suara, musik dan penyuntingan. Penggunaan kata atau kalimat dapat membawa makna tertentu ketika diterima oleh audiens, kemudian bagaimana peristiwa tersebut diorganisasikan ke dalam konvensi-konvensi yang diterima secara ideologis serta bagaimana kode-kode representasi dihubungkan dan diorganisasikan ke dalam koherensi sosial seperti kelas sosial dan kepercayaan dominan yang ada dalam masyarakat.

Representasi tokoh utama Banyu sebagai anak berkebutuhan khusus menjadi tontonan yang memilukan dan menguras airmata penonton sehingga film dapat memenuhi fungsinya sebagai fungsi artistik, industrial, komunikatif dan sebagai media pembelajaran. Kekurangan Banyu sebagai tampilan realitas karena mengidap autis menjadi media pembelajaran bagi penonton bagaimana perjuangan hidupnya yang terlahir sebagai anak yang berkebutuhan khusus namun memiliki kecerdasan dan memiliki hati yang mulia. Dari film ini, kita dapat mengambil pembelajaran dari Banyu tentang pentingnya berjuang dalam hidup, memiliki tekad yang kuat dan mengasihi orang lain. Komodifikasi kepiluan Banyu yang diangkat dalam film ini mengingatkan kita bahwa banyak anak berkebutuhan khusus (autis) tidak boleh dikucilkan, dan berhenti menganggap mereka idiot karena banyak diantara mereka yang memiliki kecerdasan di atas ratarata. Belum lagi stigma masyarakat yang menganggap penderita autis tidak akan sukses dalam hidupnya karena memiliki kekurangan. Hal ini menggambarkan betapa beratnya dan belum siapnya sebagian masyarakat menerima penyandang autis.

\section{Dancing In The Rain: Industri Budaya dan Media Pembentukan Citra}


Film Dancing in The Rain tidak bisa dilepaskan dari pembentukan citra tentang arti perjuangan kepiluan yang dialami Banyu. Film ini berhasil mengubah persepsi masyarakat bahwa film genre drama yang mengisahkan sebuah persahabatan antara anak penderita autis dengan anak normal seusianya dan menceritakan tentang arti sebuah kasih sayang di dalam keluarga sudah terlalu biasa karena plotnya sederhana. Namun citra yang terbentuk adalah rasa haru dan pilu namun bangga melihat apa yang dialami dan telah dilalui Banyu.

James Lull mengungkapkan satu konsep tentang image system yaitu suatu sistem yang digunakan untuk menggambarkan penyebaran ideologi dominan. Lull mengatakan bahwa penyebaran ideologi dominan yang efektif selalu tergantung pada penggunaan image systems secara strategis (Lull, 1995). Image systems terdiri dari ideational dan mediational. Sistem ini mengandung artikulasi lapisan-lapisan representasi ideologi dan penggunaan taktis teknologi komunikasi modern untuk mendistribusikan apa yang direpresentasikan. Apabila sistem ini berhasil, maka akan mendorong penerimaan dan sirkulasi tema-tema dominan oleh penonton. Di dalam film Dancing In The Rain digambarkan arti perjuangan, persahabatan, kasih sayang, saling melindungi serta kesabaran dan ketabahaan dalam menerima ujian hidup. Contohnya ketika Eyang Uti harus menerima kenyataan bahwa Banyu menderita austis, Eyang Widya yang sangat mengagumi ketabahan Eyang Uti yang akan tetap kuat bersama-sama menerima kondisi Banyu, ketika Kinara tabah mengetahui mengidap penyakit meningitis.

Image system juga melibatkan artikulasi dari lapisan-lapisan representasi yang jika berhasil akan mendorong penerimaan khalayak dan sirkulasi tema dominan. Sistem ini tersusun atas unitunit representasi ideasional seperti halnya morfem dalam bahasa dengan 17 bentuk pengorganisasian internal yang kompleks kemudian mengarahkan kepada interpretasiinterpretasi tertentu (Lull, 1995). Unit-unit representasi yang dimaksud adalah satuan pesanpesan media yang tampaknya berdiri sendiri namun sebenarnya memiliki pola umum yang berulang antara satu pesan dengan pesan lainnya. Di dalam film Dancing In The Rain, unit representasinya adalah pemilihan ketiga pemain utama yang secara fisik menarik. Visualisasi figur-figur fisik dan wajah yang menarik sejak awal pemilihan pemain adalah bukan tanpa alasan karena menurut Lull (1995) penjualan produk film tidak hanya memasarkan produk, jasa dan ide namun juga menampilkan figur-figur yang menarik. Di dalam film Dancing In The Rain, Dimas, Bunga dan Deva memiliki penampilan fisik yang tampan dan cantik sehingga menjadi komoditi di media karena wajah yang menarik selalu menjadi daya tarik, kemudian media massa mengakomodasi kecenderungan ini dan mengembangkannya sebagai suatu ideologi budaya dominan. Dengan kata lain, produsen film menjual sistem pembentukan ide yang berlapis-lapis dan terintegrasi yang mencakup, menginterpretasikan dan memproyeksikan citra-citra produk yang saling bergantung, mengidealkan para pemain dan penonton tetap memperoleh pesan yang disampaikan oleh film. Iflix Original selaku distributor film memperoleh keuntungan dari implikasi budaya yang mengagungkan superioritas penampilan fisik. Sutradara dan Produser film juga memperoleh keuntungan dari pemilihan pemain serta mengangkat tema autis yang menyentuh nurani untuk dijadikan film. Khalayak media sebagai konsumen didorong untuk terlibat dengan film dan pemain-pemainnya dengan membayangkan arena fisiki, konteks, situasi sosial dan keadaan emosi yang sesungguhnya di mana mereka akan dapat menggunakan produk itu. Bayangan situasi itu menurut Lull (1995) tertanam dalam struktur nilai yang melingkupinya, yang telah dikenal oleh penonton.

Image system juga melibatkan sistem mediasi. Ideologi yang disampaikan melalui film sebagian diwakilkan dalam bahasa, diartikulasikan, diinterpretasikan melalui bahasa lengkap dengan kode, kemudian digunakan oleh orang-orang dalam interaksi sosial sehari-hari. Proses ini mencakup mediasi citra yang dibagi kepada mediasi teknologis dan sosial. Mediasi teknologis menurut Lull (1995) mengacu kepada intervensi teknologi komunikasi dalam interaksi sosial. Di dalam film Dancing In The Rain dapat dijumpai pada penggunaan bahasa gambar, musik latar, dialog, dialog, efek visual, gaya plot film, editing, pengemasan produk dan marketing/promosi film untuk mencapai tujuan yang diinginkan. Sementara mediasi sosial mengacu kepada penggunaan kode dalam pergaulan sosial yang rutin. Representasi ideologis dikenali, diinterpretasi, disunting dan digunakan oleh para khalayak dalam konstruksi sosial mengenai kehidupan sehari-hari.

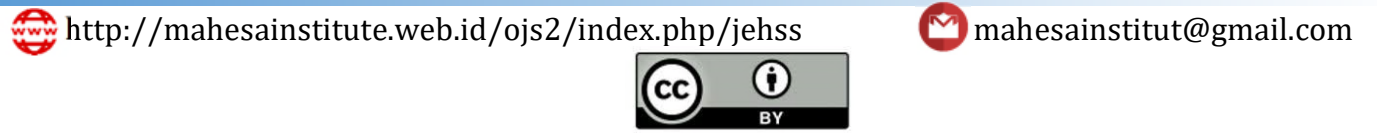

220

This work is licensed under a Creative Commons Attribution 4.0 
Vol 3, No. 1, Agustus 2020: 213 -221, DOI: https://doi.org/10.34007/iehss.v3i1.271

Film Dancing In The Rain menyatukan pembentukan sistem citra yang melibatkan sistem ideasi dan mediasi sekaligus. Di dalam sistem ideasi, menampilkan karakter Banyu penderita autis namun memiki kecerdasan dan baik hati yang bisa dijadikan contoh teladan. Di dalam sistem mediasi, terjadi pengambilan ungkapan-ungkapan dan ide ketika surat yang dituliskan Banyu untuk Eyang Uti dan sahabatnya sehingga airmata yang membanggakan serta mengangumkan dapat dipandang sebagai representasi dan komodifikasi kepiluan.

\section{SIMPULAN}

Struktur naratif dalam film Dancing in The Rain merupakan film bertema anak berkebutuhan khusus (autis) di masyarakat sebagai bentuk bahwa realitas yang dikemas sebagai produk hiburan dalam industri budaya (dalam hal ini film) dapat dijadikan sebuah media pembelajaran. Representasi dan komodikasi kepiluan yang ditampilkan, memberikan gambaran mengenai kondisi, pengalaman, serta masalah yang dihadapi tokoh utama (penderita autis) berjuang menghadapi kehidupan. Kepada masyarakat, film ini menjadi pembelajaran bagaimana beratnya dan belum siapnya sebagian masyarakat menerima penderita autis yang ingin mendapatkan perlakuan yang sama seperti anak biasa. Walaupun film bertemakan autis sudah pernah dibuat, untuk sineas Indonesia tetap memasukkan sisi ke-Indonesia-an di dalam film.

\section{DAFTAR PUSTAKA}

Adorno, T.W. \& Horkheimer, M. (2002). Dialectic of Enlightenment. California: Stanford University Press.

Akim, K., Kara-Murza, G., Saenko, N., Suharyanto, A., Kalimullin, D. (2019). Superhero movie: Breaking the challenges of topics in the modern epos. Opcion, 35(22): 1221-1236

Ayun, P.Q., (2015), Sensualitas dan Tubuh Perempuan dalam Film-film Horor di Indonesia (Kajian Ekonomi Politik Media), Jurnal Simbolika: Research and Learning in Comunication Study, 1 (1): 16-22

Briandana, R., dan Nindyta A.D., (2015), Dinamika Film Komedi Indonesia Berdasarkan Unsur Naratif (Periode 1951-2013), Jurnal Simbolika: Research and Learning in Comunication Study, 1 (2): $109-117$

Dalimunthe S.R.K, Hendra, Y \& Matondang, A (2020). Persepsi Masyarakat Tentang Persahabatan dalam Film 5 cm (Studi Deskriptif Pada Siswa SMK Negeri 1 Barumun Padang Lawas). PERSPEKTIF, 9 (1): 38-45.

Eric, S., et.al. (2011). Menjegal Film Indonesia: Pemetaan Ekonomi Politik Industri Film Indonesia. Jakarta: Rumah Film dan Yayasan TIFA.

Eriyanto. (2001). Analisis Wacana: Pengantar Analisis Teks Media. Yogyakarta: LkiS.

Irawanto, B. (2004). Hegemoni Militer dalam Sinema Indonesia: Sebuah Analisis Semiotik. Yogyakarta: Gadjah Mada University Press.

Keraf, G. (2000). Diksi dan Gaya Bahasa. Jakarta: PT Gramedia Pustaka Utama.

Kracauer, S. (1947). From Caligari to Hitler: A Psychological History of the German Film. Princeton University Press, New Jersey.

Lotman, J. (1976). Semiotics of Cinema. An Arbour: University of Michigan.

Lull, J. (1995). Media, Communication, Culture: A Global Approach. New York: Polity Press.

Marahimin, I. (1994). Menulis Secara Populer. Jakarta: Pustaka Jaya.

Prakosa, G. (2001). Film Pinggiran: Antologi Film Pendek, Film Eksperimental dan Film Dokumenter. Jakarta: FFTV-IKJ.

Pranajaya, A. (1999). Film dan Masyarakat: Sebuah Pengantar. Jakarta: BP SDM CITRA.

Sarup, M. (2003). Post-Strukturalism End Postmodernism. Yogyakarta: Jendela.

Semi, A. (2003). Menulis Efektif . Padang: Angkasa Raya.

Sobur, A. (2014). Komunikasi Naratif, paradigma, Analisis dan Aplikasi. Bandung: PT Remaja Rosdakarya. Sugiono. (2007). Memahami Penelitian Kualitatif. Bandung: Alfabeta.

Thawites, T., D, L. \& Mules, W. (2002). Introducing Cultural and Media Studies : A Semotic Approach 2nd ed. Houndmills, Basingstoke, UK: Palgarave.

Vincent, M. (2009). The Political Economy of Communication 2nd Edition. London: Sage Publication.

Widjono, H.S. (2007). Bahasa Indonesia Mata Kuliah Pengembangan Kepribadian di Perguruan Tinggi (Rev). Jakarta: Grasindo.

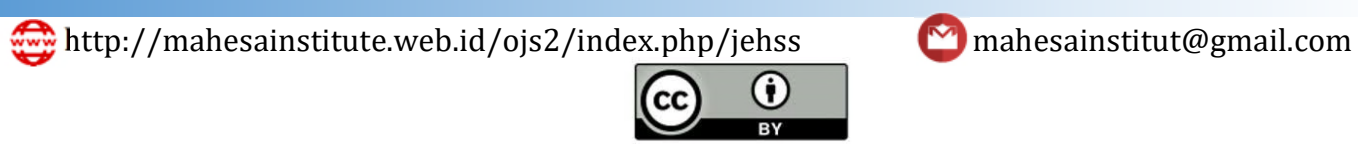


Ilma Saakinah Tamsil, Representasi dan Komodifikasi Kepiluan dalam Film Dancing In The Rain 